\title{
A collagen-silica-based biocomposite for potential application in bone tissue engineering
}

\author{
María Alvarez Echazú ${ }^{1,2,4}$ | Sandra Renou ${ }^{2}$ | Gisela Alvarez ${ }^{1,3}$ | \\ Martin Desimone $^{1,3}$ (1) | Daniel Olmedo ${ }^{2,4}$
}

${ }^{1}$ Universidad de Buenos Aires, Facultad de Farmacia y Bioquímica. Cátedra de Química Analítica Instrumental, Buenos Aires, Argentina

${ }^{2}$ Universidad de Buenos Aires, Facultad de Odontología, Cátedra de Anatomía Patológica, Buenos Aires, Argentina

${ }^{3}$ Consejo Nacional de Investigaciones Científicas y Técnicas (CONICET), Instituto de Química y Metabolismo del Fármaco (IQUIMEFA), Facultad de Farmacia y Bioquímica, Universidad de Buenos Aires, Buenos Aires, Argentina

${ }^{4}$ Consejo Nacional de Investigaciones Científicas y Técnicas (CONICET), Buenos Aires, Argentina

\section{Correspondence}

Daniel Olmedo, Universidad de Buenos Aires, Facultad de Odontología, Cátedra de Anatomía Patológica, Buenos Aires, Argentina. Email: daniel.olmedo@odontologia.uba.ar, olmedodg@gmail.com

Funding information Consejo Nacional de Investigaciones Científicas y Técnicas, Grant/Award Number: 11220130100091; FOUBA, Grant/Award Number: Res. (CD) №330/19-01; Ministerio de Ciencia, Tecnología e Innovación Productiva, Grant/Award Number: 2015-2922; Universidad de Buenos Aires, Grant/Award Numbers: 20020110100081, UBACYT 20020150100032BA, UBACYT 20020190100148BA

\begin{abstract}
Bone is a hierarchical material that has inspired the design of biopolymer-derived biocomposites for tissue engineering purposes. The present study sought to synthesize and perform the physicochemical characterization and biocompatibility of a collagensilica-based biocomposite for potential application in bone tissue engineering. Ultrastructure, biodegradability, swelling behavior, and biocompatibility properties were analyzed to gain insight into the advantages and limitations to the use of this biomaterial as a bone substitute. Scanning electron microscopy analysis showed a packedcollagen fibril matrix and silica particles in the biocomposite three-dimensional structure. As shown by analysis of in vitro swelling behavior and biodegradability, it would seem that the material swelled soon after implantation and then suffered degradation. Biocompatibility properties were analyzed in vivo 14-days postimplantation using an experimental model in Wistar rats. The biocomposite was placed inside the hematopoietic bone marrow compartment of both tibiae $(n=16)$. Newly formed woven bone was observed in response to both materials. Unlike the pure-collagentissue interface, extensive areas of osseointegration were observed at the biocomposite-tissue interface, which would indicate that silica particles stimulated new bone formation. Agglomerates of finely particulate material with no inflammatory infiltrate or multinucleated giant cells were observed in the bone marrow implanted with the biocomposite. The biocomposite showed good biocompatibility properties. Further studies are necessary to evaluate their biological behavior over time.
\end{abstract}

KEYWORDS

biocompatibility, biocomposite, bone tissue engineering, collagen, silica

\section{1 | INTRODUCTION}

Biopolymer-derived biocomposites have emerged as a promising alternative for the management of bone defects and fractures. Indeed, properties such as their biocompatibility ${ }^{1}$ and biodegradability ${ }^{2}$ have been pointed out as suitable properties for bone tissue engineering. Collagen-derived biocomposites, in particular, are promising for bone grafting, since bone tissue is mainly composed of mineralized collagen fibrils. $^{3}$ A number of biomaterials have been developed considering the natural architecture of bone. ${ }^{4-6}$ It continues to be a challenge to synthesize a biomaterial that exactly mimics the organization and function of bone tissue. Bone is a hierarchical material with heterogeneous structure and chemistry across multiple length scales. ${ }^{7}$ The application of several synthetic polymers as synthetic bone substitutes has been studied extensively. ${ }^{8}$ However, the use of natural polymers for the design of novel bone substitutes, such as collagen, has 
increased because they can easily mimic the extracellular matrix (ECM). ${ }^{9}$ Collagen molecules form the major part of tissues like bone, cornea, or tendon where they are organized into ordered fibrillar networks. ${ }^{9}$ Collagen type I can be purified in vitro, and fibrillar matrices that strongly mimic collagen tissue organizations can be obtained by a self-assembling process. In fact, fibroblast interactions with collagen matrices as well as their interactions with collagen associated with minerals, which mimic the bone structure, have been widely studied. ${ }^{10,11}$

The major components of bone are collagen, carbonated hydroxyapatite, water, noncollagenous proteins, and proteoglycans. ${ }^{3}$ In the present study, collagen type I was used as the organic phase and solid silica particles (Sol-Si) were used as the mineral phase to synthesize a collagen-silica biocomposite (C/Sol-Si).

Silica, a ceramic biomaterial, has been processed to obtain particles, xerogels, and films for many biomedical purposes. ${ }^{12,13}$ Silica particles have been shown to have intrinsic biological activity, and their versatility allows varying their size and surface and thus modulating a range of cell-specific biological responses for therapeutic benefit. ${ }^{14,15}$ Moreover, several ions, including silicate ion, have been shown to be capable of inducing osteoblast precursor differentiation through growth factor signaling pathways and stimulating other processes that promote bone tissue growth. In addition, there are a number of advantages to using these ions as compared to protein growth factors to induce bone tissue repair, including lower cost, greater simplicity, and higher stability. ${ }^{16}$

The present study sought to synthesize a collagen-silica-based biocomposite and physicochemically characterize the obtained material by scanning electron microscopy (SEM), transmission electron microscopy (TEM), and Fourier transform infrared (FT-IR). Swelling and biodegradability properties were also evaluated.

In addition, a (3 T3) mouse fibroblast cytotoxicity assay and an in vivo study were performed to assess the advantages and limitations to using the biomaterial obtained here as a bone substitute.

\section{2 | MATERIALS AND METHODS}

\section{1 | Materials}

MTT (thiazolyl blue tetrazolium bromide) reagent, collagenase type I, and tetraethyl orthosilicate (TEOS) $98 \mathrm{wt} \%$ were purchased from Sigma-Aldrich. Ammonium hydroxide solution 30\% was purchased from Carlo Erba Reagents. Dulbecco's modified Eagle's medium (DMEM), fetal bovine serum, penicillin, and streptomycin were purchased from Gibco. All other reagents were of analytical grade.

\subsection{Collagen type I extraction}

Collagen type I was obtained from rat tails. Internal fibers were isolated and washed three times using phosphate buffered saline (PBS). The fibers were then placed in a $0.5 \mathrm{M}$ sterile acetic acid solution and stirred at $4^{\circ} \mathrm{C}$ for $48 \mathrm{hr}$. The obtained colloid was centrifuged; the supernatant was removed and placed in a $4 \mathrm{M} \mathrm{NaCl}$ solution at a final concentration of $1 \mathrm{M} \mathrm{NaCl}$ and stored overnight at $4^{\circ} \mathrm{C}$. The pellet was dialyzed for $72 \mathrm{hr}$ against a $0.5 \mathrm{M}$ acetic acid solution using a 12,000-14,000 molecular weight cut-off dialysis tubing.

\section{3 | Sol-Si particle synthesis}

Sol-Si particles were synthesized according to the Stöber method. ${ }^{17}$ Briefly, TEOS was added to a solution of ammonium hydroxide in a water/ethanol mixture to obtain silica particles approximately $500 \mathrm{~nm}$ in diameter. The solution was stirred at room temperature for $24 \mathrm{hr}$, and the particles were recovered by centrifugation and washed with deionized water until neutral $\mathrm{pH}$ was reached. Sol-Si concentration was determined by weighing the residual mass of an aliquot dried at $80^{\circ} \mathrm{C}{ }^{18}$

\section{$2.4 \quad$ C/Sol-Si synthesis}

The concentration of the collagen colloid was determined by hydroxyproline titration. ${ }^{19}$ Following, $1 \mathrm{ml}$ of $5 \mathrm{mg} / \mathrm{ml}$ of collagen colloid together with $5 \mathrm{mg}$ of Sol-Si particles were mixed and exposed to ammonia vapors in order to neutralize the acid and form the corresponding hydrogel. The biocomposite was then dried in an oven at $37^{\circ} \mathrm{C}$ and cut with a scalpel to obtain laminar implants measuring $6.0 \times 1.0 \times 1.0 \mathrm{~mm}^{3}$. The implants were used to assess biological response in vivo and to perform the (3 T3) mouse fibroblast cytotoxicity assay in vitro.

\subsection{DLS characterization of (Sol-Si) particles}

Hydrodynamic size (Dh), size distribution (polydispersity index, PDI), and z potential of the Sol-Si particles were assayed in Milli-Q water by dynamic light scattering (DLS) using a Zeta sizer Nano-ZS (Malvern Instruments, Malvern, UK) at a scattering angle of $173^{\circ}$ and a fixed measurement position of $4.65 \mathrm{~mm}$. Temperature was controlled at $25 \pm 0.1^{\circ} \mathrm{C}$. Viscosity was $0.8872 \pm 0.0016 \mathrm{cP}\left(25^{\circ} \mathrm{C}\right)$ and refractive index (RI) was 1.33 . Values are expressed as mean $\pm S D$ of triplicate experiments.

\section{6 | Ultrastructural characterization of Sol-Si particles and the $\mathrm{C} / \mathrm{Sol}-\mathrm{Si}$ biocomposite}

The shape and appearance of the particles were analyzed by SEM and TEM. The particles were gold-sputtered in an argon atmosphere before analysis by SEM (Zeiss Supra 40 SEM microscope). For TEM, small drops of Sol-Si particles in aqueous solution were placed on carbon-coated copper grids. After $1 \mathrm{~min}$, the liquid was blotted using filter paper and the sample was analyzed by TEM (Zeiss 109) at room temperature.

Prior to analysis by SEM (Zeiss SUPRA 40 microscope), samples of the $\mathrm{C} / \mathrm{Sol}-\mathrm{Si}$ and pure collagen $(\mathrm{C})$ were fixed in a glutaraldehyde 
solution ( $10 \% \mathrm{vol} / \mathrm{vol}$ in PBS) at $4^{\circ} \mathrm{C}$ for $1 \mathrm{hr}$. After fixing, the samples were washed three times with $\mathrm{PBS}$ and frozen at $-80^{\circ} \mathrm{C}$. Finally, the $\mathrm{C} / \mathrm{Sol}-\mathrm{Si}$ and $\mathrm{C}$ samples were freeze-dried and gold sputter-coated.

The C/Sol-Si was also analyzed using TEM. To this end, samples of the biocomposite were fixed and washed as described above, after which they were post-fixed using $5 \%$ osmium tetroxide in cacodylate/ saccharose buffer $\mathrm{pH} 7.4(0.05 \mathrm{M} / 0.3 \mathrm{M})$ at $4^{\circ} \mathrm{C}$ for $1 \mathrm{hr}$. The samples were then dehydrated and embedded in epoxy resin. Thin sections were obtained using an ultramicrotome and contrasted by phosphotungstic acid. The recovered sections were imaged using a Zeiss 109 microscope.

\section{7 | FT-IR spectroscopy characterization}

FT-IR spectra of the $\mathrm{C} / \mathrm{Sol}-\mathrm{Si}, \mathrm{C}$, and Sol-Si particles were collected using an FT-IR-Raman Thermo Scientific Nicolet model 50 computer IS, coupled with an attenuated total reflection device (ATR). The scanning range was $4,000-500 \mathrm{~cm}^{-1}$, and the spectra were processed using Thermo Nicolet OMNIC software.

\section{8 | Swelling study}

Samples of the C/Sol-Si and C were freeze-dried, weighed $\left(\mathrm{W}_{\mathrm{o}}\right)$, and stored in PBS to allow water uptake. At the corresponding time points $(t)$, a set of samples was removed from the PBS, the excess water was removed, and the samples were weighed. The degree of swelling was calculated using the following equation:

$$
\mathrm{W} \%=[(\mathrm{W}-\mathrm{Wo}) / \mathrm{W}] \times 100
$$

Water content at equilibrium $\left(\mathrm{W}_{\infty}\right)$ and kinetic rate constants were calculated according to the following equation:

$$
t / W=1 /(K W 2 \infty)+t / W_{\infty}
$$

\section{9 | Collagenase type I assay}

Collagenase degradation of the C/Sol-Si and pure collagen was studied in the presence of collagenase type I (Gibco, $260 \mathrm{U} / \mathrm{mg}$ ) using $1 \mathrm{ml}$ of a collagenase type I/PBS suspension at a final concentration of $15 \mathrm{U} / \mathrm{ml}, \mathrm{pH}$ 7.4. Samples of the $\mathrm{C} / \mathrm{Sol}-\mathrm{Si}$ and $\mathrm{C}$ were incubated in the presence of the enzyme at $37^{\circ} \mathrm{C}$. The samples were collected at specific time intervals, washed with distilled water, centrifuged, freeze dried, and weighed $(n=3)$.

\subsection{Cell culture and cytotoxicity test}

(3 T3) mouse fibroblast cells were grown in adherent culture flasks containing low-glucose DMEM supplemented with $10 \%$ heat- inactivated fetal bovine serum and $1 \%$ penicillin-streptomycin. The samples were kept at $37^{\circ} \mathrm{C}$ in a humidified $5 \%$ carbon dioxide chamber until confluence was reached. Harvesting was performed using trypsin-EDTA solution. Cells were stained with trypan blue and counted with a Neubauer chamber.

Fibroblast cells $\left(4.0 \times 10^{4}\right)$ were seeded in each well and added with $1 \mathrm{ml}$ of complete low-glucose DMEM and incubated for $48 \mathrm{hr}$. Samples of the $\mathrm{C} / \mathrm{Sol}-\mathrm{Si}$ and of $\mathrm{C}$ were then placed on the fibroblast layer in the 24 wells, and cell metabolic activity was measured after $24 \mathrm{hr}$ using the MTT assay. The medium was removed and replaced with $0.5 \mathrm{ml}$ of $0.5 \mathrm{mg} / \mathrm{ml}$ MTT solution. The samples were incubated in a humidified $5 \%$ carbon dioxide chamber for $4 \mathrm{hr}$. The MTT solution was then removed, $1 \mathrm{ml}$ of absolute ethanol was added, and the mixtures were incubated at room temperature for $30 \mathrm{~min}$. Absorbance was measured at $570 \mathrm{~nm}$ in a UV-visible spectrophotometer (Cecil CE 3021, Cambridge, England).

\subsection{1 | In vivo study}

\subsection{1 | Surgical procedure}

Biological response to the $\mathrm{C} / \mathrm{Sol}-\mathrm{Si}$ was studied in male Wistar rats ( $n=8$, mean body weight: $120 \mathrm{~g}$ ) fed ad libitum. The animals were anesthetized intraperitoneally with a solution of $8 \mathrm{mg}$ of Ketamine chlorhydrate (Fort Dodge, Argentine) and $1.28 \mathrm{mg}$ of Xylazine (Bayer, Germany) per $100 \mathrm{mg}$ of body weight. The skin of both tibiae was shaved prior to performing a $1.5 \mathrm{~cm}$ incision along the tibial crest. The subcutaneous tissue, muscles, and ligament were dissected to expose the lateral external surface of the diaphyseal bone. A hole measuring $1.5 \mathrm{~mm}$ in diameter was made in the bone with an end cutting bur, using manual rotating movements to avoid overheating and necrosis of the bone tissue. Laminar implants of the $\mathrm{C} / \mathrm{Sol}-\mathrm{Si}\left(6.0 \times 1.0 \times 1.0 \mathrm{~mm}^{3}\right)$ were placed in the hematopoietic bone marrow compartment of both tibiae $(n=16)$, parallel to their longest axis (Figure 1). A separate stitch suture was performed. No antibiotic therapy was administered. ${ }^{20}$

For evaluation of tissue response to pure collagen, a separate group of animals $(n=4)$ was subjected to implantation of a sample of $\mathrm{C}$ inside the medullary compartment of both tibiae using the same experimental model.

All the animals were euthanized by an overdose of anesthetic 14 days post-implantation. The tibiae were resected, radiographed, and fixed in $10 \%$ buffered formalin solution. All animal procedures were performed in keeping with the guidelines of the National Institutes of Health (NIH Publication-Guide for the Care and Use of Laboratory Animals): Eighth Edition (2011) and the guidelines of the School of Dentistry, Buenos Aires University (Res [CD] 352/02 and Res [CD] 694/02) for the care and use of laboratory animals. The protocol was approved by the institutional experimentation committee (School of Dentistry of the University of Buenos Aires, Resolution Number 009/2019- CICUAL-ODONFOUBA). 


\subsection{2 | Histological processing}

The tibiae $(n=24)$ were demineralized in $10 \%$ ethylenediaminetetraacetic acid (EDTA, Anhedra, Argentina); the acid solution was renewed every 3 days for 20 days. After demineralization, the samples were embedded in paraffin to obtain $10 \mu \mathrm{m}$ thick cross-sections

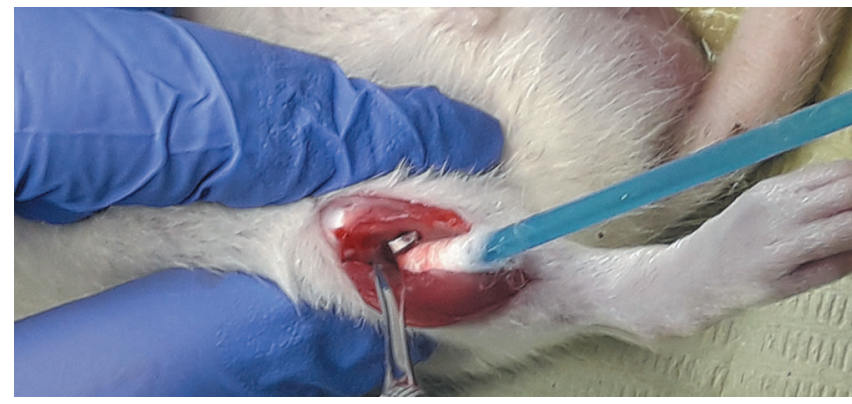

FIGURE 1 Photograph showing the in vivo procedure: A laminar implant (C/Sol-Si or pure collagen) is inserted inside the medullary compartment through a hole made in the tibial bone. C/Sol-Si, collagen-silica biocomposite at the level of the biocomposite or $\mathrm{C}$ implant. The obtained sections were stained with hematoxylin-eosin, and histological examination was performed using a light microscope (Leica, DM 2500, Germany).

\subsection{Statistics}

Data are shown as mean $\pm S D$ of at least triplicate experiments and results of the MTT assay were analyzed using Student's t-test. Statistical significance was set at a value of $p<.05$

\section{$3 \mid$ RESULTS}

\section{1 | DLS characterization of Sol-Si particles and ultrastructural characterization of Sol-Si particles and the $\mathrm{C} /$ Sol-Si biocomposite}

As shown by SEM and TEM, Sol-Si particles prepared following the Stöber method were spherical in shape; they were distributed homogeneously and particle aggregation was not significant (Figure 2a,b).
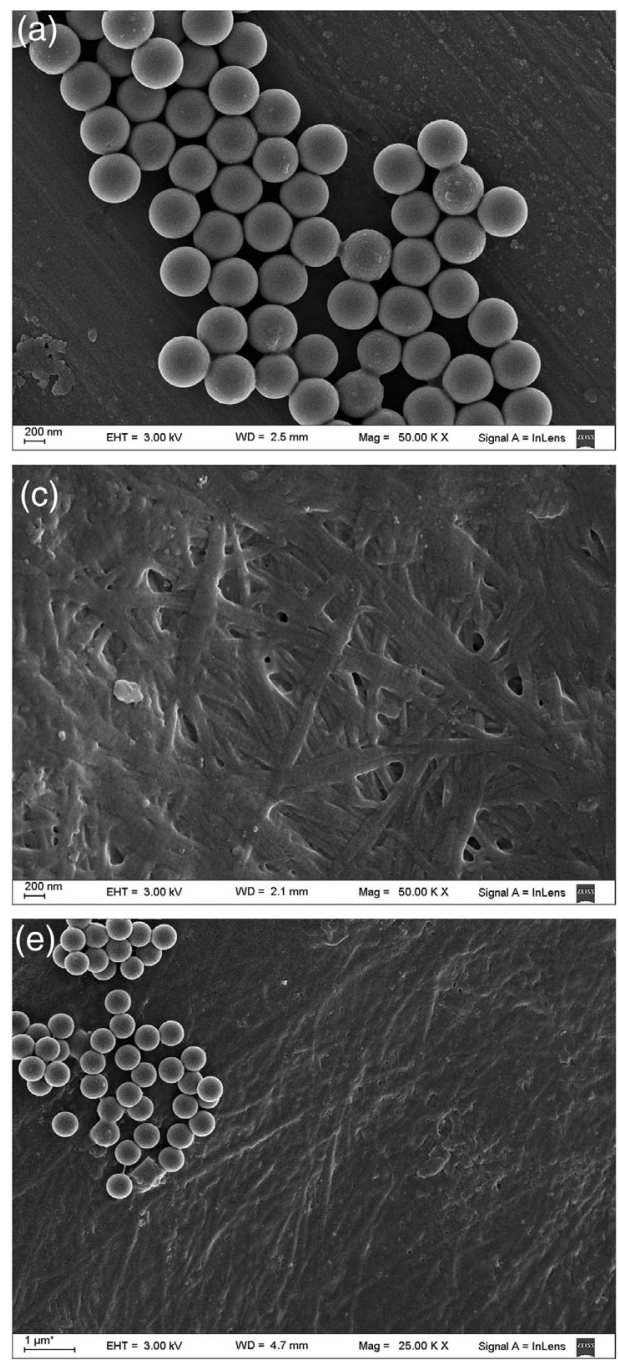
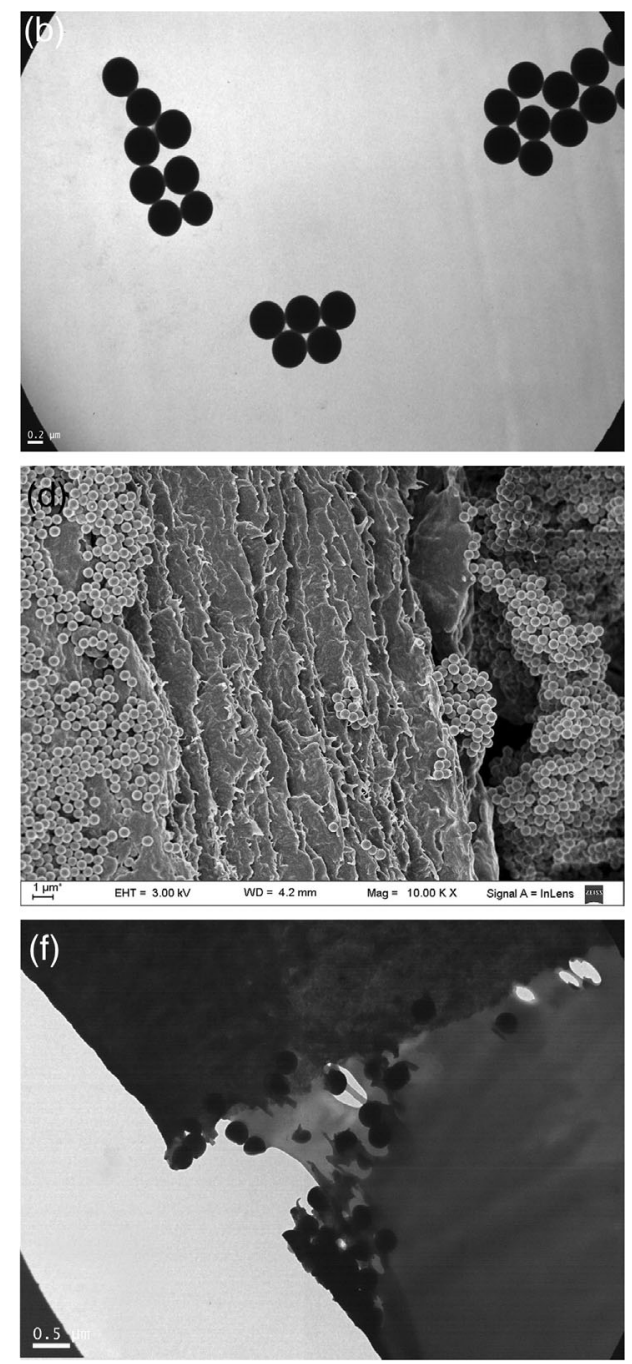

FIG URE 2 (a) SEM image of SolSi particles; (b) TEM image of Sol-Si particles; (c) SEM image of Pure collagen; (d-e) SEM image of the (C/Sol-Si) biocomposite; (f) TEM image of the (C/Sol-Si) biocomposite. $\mathrm{C} / \mathrm{Sol}-\mathrm{Si}$, collagen-silica biocomposite; SEM, scanning electron microscopy; TEM, transmission electron microscopy 
TABLE 1 DLS characterization of (Sol-Si) particles

\begin{tabular}{llll} 
& Particle size $(\mathrm{nm}) \pm S D$ & PDI $\pm S D$ & Zeta-potential $(\mathrm{mV}) \pm S D$ \\
Sol-Si & $488.9 \pm 5.8$ & $0.044 \pm 0.023$ & $-41.4 \pm 0.6$ \\
\hline
\end{tabular}

Abbreviations: PDI, polydispersity index; Sol-Si, solid silica.

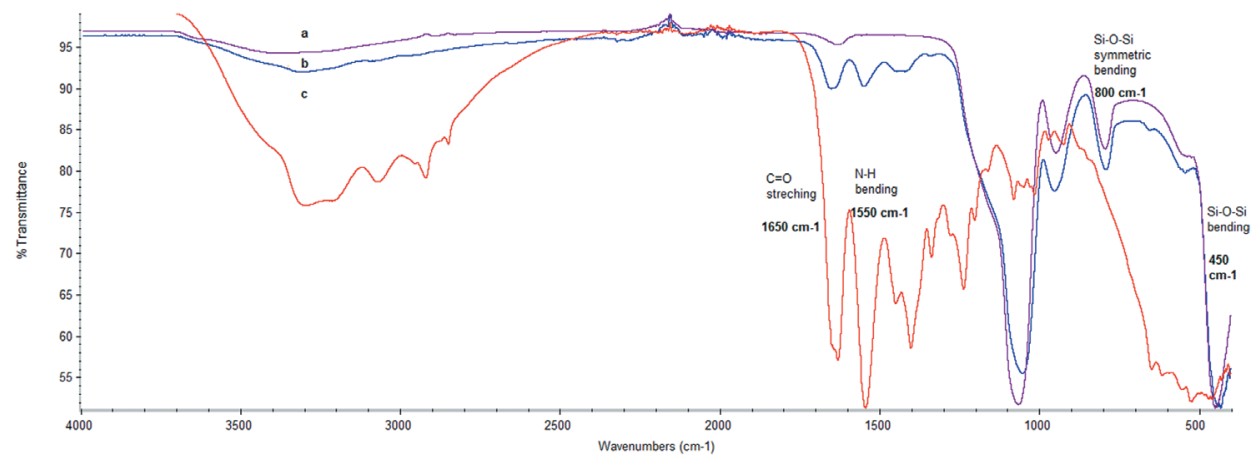

the C/Sol-Si in phosphate-buffered saline over a period of $24 \mathrm{hr}$.

(b) Pure collagen and $\mathrm{C} / \mathrm{Sol}-\mathrm{Si}$ experimental data of water content and time plotted according to a second-order kinetic model. Data are shown as mean $\pm S D$ of triplicate experiments $(n=3)$. C/Sol-Si, collagen-silica biocomposite (a)
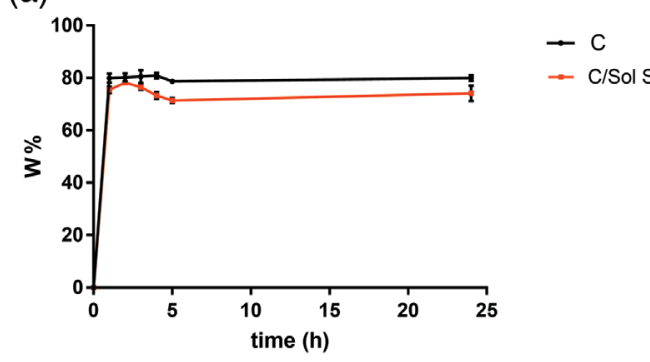

(b)

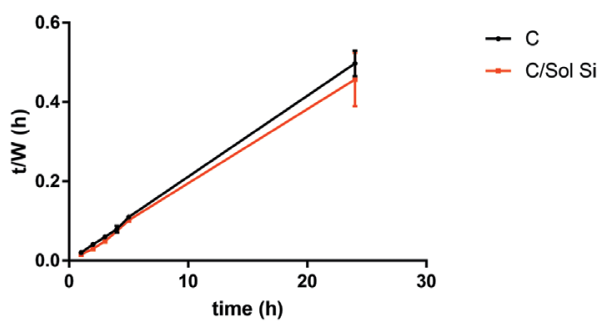

According to the DLS characterization, mean hydrodynamic size was $488.9 \pm 5.8$, as detailed in Table 1. Zeta potential $\zeta$ was $-41.4 \pm 0.6$, which was expected considering the silanol groups on the surface of the particles. ${ }^{18}$

Pure collagen SEM images (Figure 2c) showed a dense fibrillar collagen network, with fibrils measuring approximately $100 \mathrm{~nm}$ in diameter. The observed matrix was composed of a network of overlapping and banded fibrils, and was not altered by the addition of the Sol-Si particles (Figure 2d,e).

The biocomposite (Figure 2f) exhibited a sheet-like structure with Sol-Si particles, probably because of the densely packed collagen network.

\section{2 | FT-IR characterization}

FT-IR characterization was performed on Sol-Si particles and samples of $\mathrm{C} / \mathrm{Sol}-\mathrm{Si}$ and $\mathrm{C}$ (Figure 3). To this end, the characteristic functional groups $^{21,22}$ of the tested samples were determined based on the IR absorption range. The Sol-Si particles showed characteristic IR bands in the region of $800 \mathrm{~cm}^{-1}$ (Si-O-Si symmetric stretching) and $450 \mathrm{~cm}^{-1}$ ( $\mathrm{Si}-\mathrm{O}$ bending). The pure collagen exhibited absorption bands corresponding to $\mathrm{C}=\mathrm{O}$ stretching (Amide $\mathrm{I}$ ) and $\mathrm{N}-\mathrm{H}$ bending (Amide II) at 1,650 and $1,550 \mathrm{~cm}^{-1}$, respectively. The $\mathrm{C} / \mathrm{Sol}-\mathrm{Si}$ showed the characteristic bands of collagen and silica described above, indicating the coexistence of both biomaterials in the composite structure.

\subsection{Swelling study}

It has been shown that early swelling facilitates cell attachment and proliferation. ${ }^{23}$ Most natural polymers, such as collagen, swell in biological fluids. Swelling behavior of the $\mathrm{C}$ and $\mathrm{C} / \mathrm{Sol}-\mathrm{Si}$ in PBS within the first $24 \mathrm{hr}$ is shown in Figure $4 \mathrm{a}$.

Pure collagen and the $\mathrm{C} / \mathrm{Sol}-\mathrm{Si}$ reached swelling equilibrium in $1 \mathrm{hr}$, and the swelling process followed second order kinetics (Figure 4b). As shown in Table 2, water content in equilibrium $\left(W_{\infty}\right)$ of C was $-80 \%$, and it decreased slightly with the addition of the Sol-Si particles. Pure collagen and the $\mathrm{C} / \mathrm{Sol}-\mathrm{Si}$ had the ability to absorb a high amount of water.

\section{4 | Collagenase type I assay}

The percentage of weight loss of $\mathrm{C}$ and the $\mathrm{C} / \mathrm{Sol}-\mathrm{Si}$ at the studied time points is shown in Figure 5. The percentage of degradation of pure collagen at $24 \mathrm{hr}$ was higher than that of the C/Sol-Si. The collagen fibrils in pure collagen were more prone to enzymatic 
TABLE 2 Pure collagen and C/Sol-Si water content at equilibrium $\left(W_{\infty}\right)$ and coefficient of determination $\left(r^{2}\right)$ of water content and time plotted according to a second-order kinetic model

\begin{tabular}{lll} 
& $\mathrm{W}_{\infty}$ & $\mathrm{r}^{2}$ \\
$\mathrm{C}$ & 79.95 & 0.9998 \\
$\mathrm{C} /$ Sol-Si & 74.28 & 0.9978 \\
\hline
\end{tabular}

Abbreviation: C/Sol-Si, collagen-silica biocomposite.

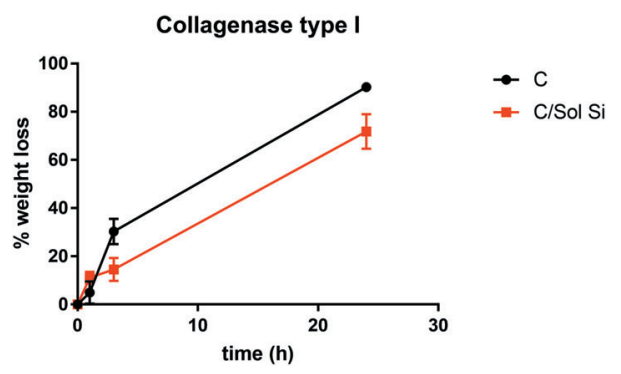

FIGURE 5 Accelerated enzymatic degradation of acellular biomaterials by collagenase digestion. Percentage of weight loss of pure collagen and the $\mathrm{C} / \mathrm{Sol}-\mathrm{Si}$ through time. Data are shown as mean $\pm S D$ of triplicate experiments $(n=3)$. C/Sol-Si, collagen-silica biocomposite

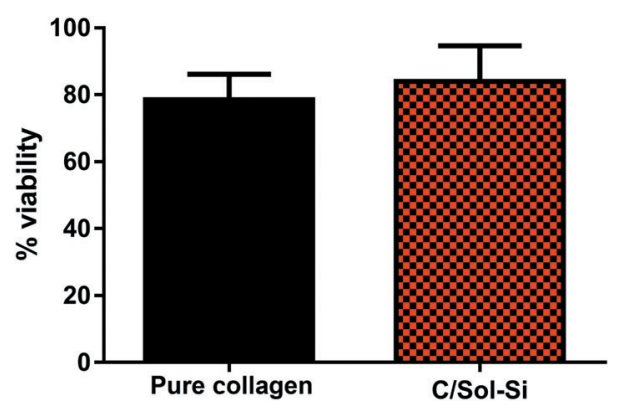

FIGURE 6 Cell viability of (3 T3) mouse fibroblasts after incubation with $\mathrm{C}$ and the $\mathrm{C} / \mathrm{Sol}-\mathrm{Si}$ for $24 \mathrm{hr}$, using colorimetric MTT assay. Data are expressed as \% of viability relative to control. Data are shown as mean $\pm S D$ of triplicate experiments. $(n=3)$. C/Sol-Si, collagen-silica biocomposite degradation, as shown by $\sim 90 \%$ weight loss observed in $\mathrm{C}$ as compared to $\sim 70 \%$ weight loss observed in C/Sol-Si.

\subsection{Cell culture and cytotoxicity test}

Pure collagen and C/Sol-Si cytotoxicity against (3 T3) mouse fibroblasts using MTT assay is shown in Figure 6. For this purpose, cell metabolic activity was measured after placing the study materials on a layer of fibroblasts. Material cytotoxicity can be rated based on cell viability relative to controls, where an activity level relative to controls of $<30 \%$ is severe cytotoxicity, between 30 and $60 \%$ is moderate cytotoxicity, between 60 and $90 \%$ is slight cytotoxicity, and $>90 \%$ is no cytotoxicity. ${ }^{24,25}$ According to the above rating, both biomaterials were found to have a slight cytotoxic effect within the acceptable range for biomedical applications. In addition, comparison using Student's $t$ test showed no statistically significant difference $(p<.05)$.

\subsection{In vivo study}

No changes in animal body weight or behavior and no animal deaths were recorded throughout the entire experimental period.

\subsection{1 | Histological analysis}

Histologic examination of the tested materials, that is, C/Sol-Si and C, by light microscopy showed both had good biocompatibility properties, as evidenced by the absence of inflammation and multinucleated giant cells close to the biomaterial. As to new bone formation, large areas of woven bone (immature bone, as confirmed by polarized light microscopy) were observed at the biomaterial/tissue interface in close contact with the $\mathrm{C} / \mathrm{Sol}-\mathrm{Si}$ (osseointegration) (Figure 7a,b). As regards tissue-response to pure collagen, woven bone tissue was only observed at very few sites at the biomaterial-tissue interface (Figure 8).

Moreover, histologic examination of the C/Sol-Si showed the presence of granule-like agglomerates of a finely particulate material that was not refringent under polarized light, and no inflammation or
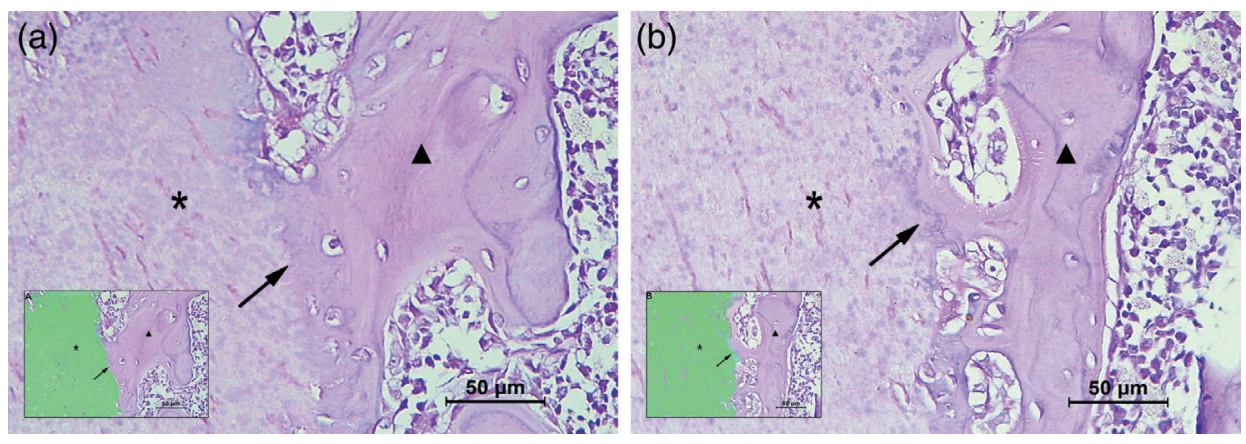

FIGURE 7 Histological examination of the $\mathrm{C} / \mathrm{Sol}-\mathrm{Si} 14$ days post-implantation (a) and (b) Note the presence of woven bone $(\boldsymbol{\Delta})$ in close contact with the biocomposite $\left({ }^{*}\right)$ (osseointegration) at the biomaterialtissue interface ( $\uparrow)$. Orig. Mag. X400. $\mathrm{H}$-E Stain. The inset shows the biocomposite area. C/Sol-Si, collagensilica biocomposite 


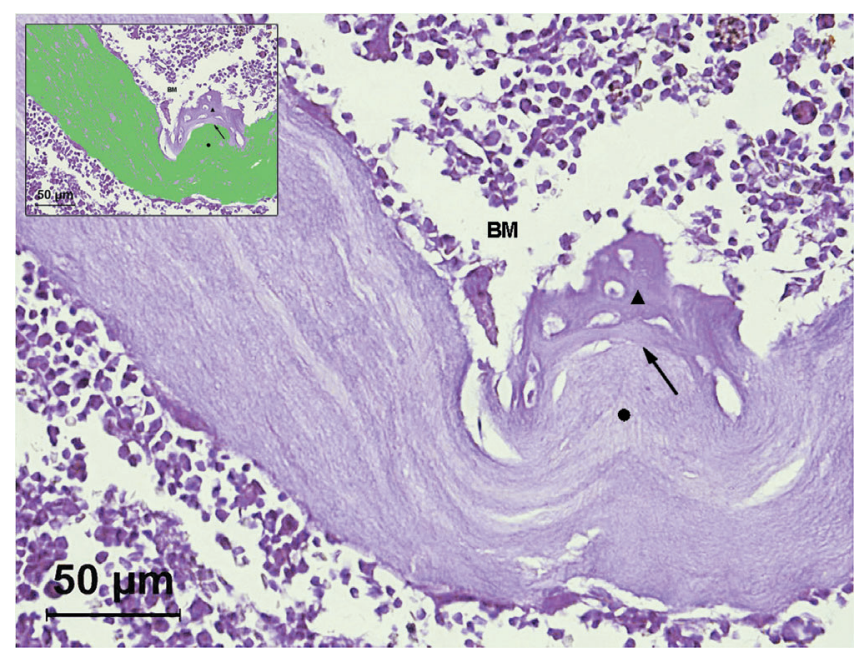

FIGURE 8 Histological study of pure collagen 14 days postimplantation. Pure collagen ( $\mathbf{O}$ can be seen surrounded by bone marrow (BM). No inflammatory infiltrate or multinucleated giant cells can be observed. Note small areas of woven bone $(\boldsymbol{\Lambda})$ in close contact (osseointegration) with the biomaterial ( $\uparrow$ ). Orig. Mag. X400. H-E Stain. The inset shows the biocomposite area. C/Sol-Si, collagen-silica biocomposite

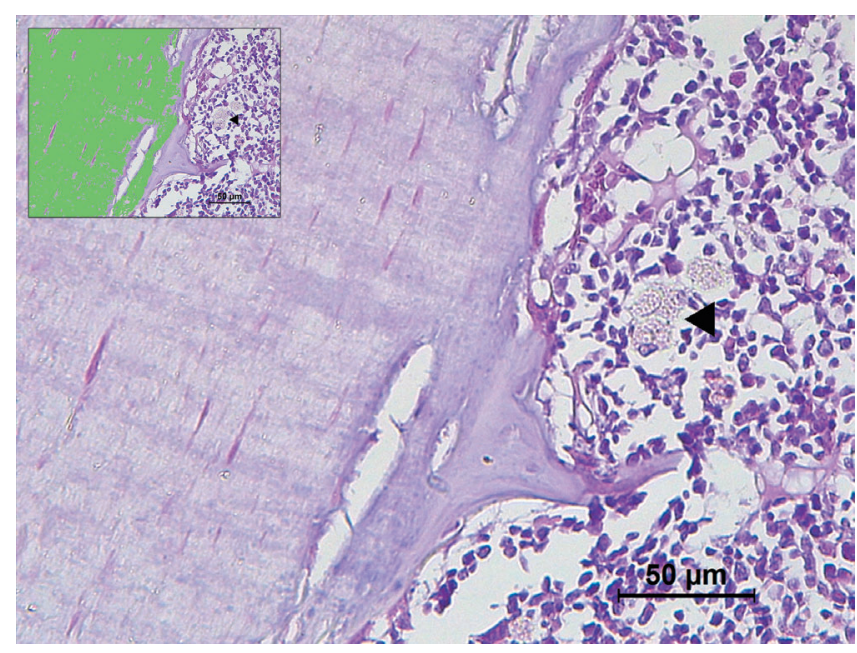

FIGURE 9 Histological study of the C/Sol-Si 14 days postimplantation. Granule-like clusters of a finely particulate material (४) can be observed inside the bone marrow (BM); no inflammatory infiltrate can be seen in contact with the clusters. The inset shows the biocomposite area. C/Sol-Si, collagen-silica biocomposite

multinucleated giant cells close to the biomaterial (Figure 9). Of note, no similar deposits were found close to pure collagen.

\section{4 | DISCUSSION}

As described by Wingender et al., ${ }^{26}$ lamellar bone has a mesoscale arrangement in which adjacent lamellae of dense, parallel fibril arrays have offset orientations between neighboring layers. The thickness and rotational offset of lamellae can vary, but is usually on the order of a few microns. The biocomposite obtained here did not exhibit the same organized lamellar bone microstructure. Nevertheless, the biomaterial consisting of a densely packed-collagen fiber matrix combined with silica particles served as a scaffold, promoting the natural bone formation process. It is noteworthy that it is not necessary for the biomaterial to resemble the bone structure since it is a temporary resorbable substitute material for promoting bone repair. A number of properties have been found to contribute significantly to biocompatibility, including porosity, surface topography, biodegradability, and bioresorbability. ${ }^{27}$ The biocomposite shown here formed without covalent crosslinking and behaves as a carrier material made of collagen, which allows introducing silica nanoparticles into the tissue during surgery.

The originality of the present study is that we assessed tissue response to the biocomposite in vivo. The basic principle of the experimental model used here, which was developed by our research team, is the osteogenic capacity of the rat tibia bone marrow. This animal model has been used to evaluate different systemic and local factors that influence tissue repair. ${ }^{20}$ It poses the advantage of providing a microenvironment that is not exposed to microbial contamination and is not subjected to mechanical forces. It thus allows objectively evaluating tissue response, ruling out confounding variables. Of note, immobilization of the biomaterial at the surgical site is essential to adequate bone repair. This variable was controlled in our in vivo model since the biomaterial remained in the same place and position inside the medullary compartment throughout the entire experimental period, and thus behaved as a 3D osteoconductive scaffold.

Histological analysis of new bone formation showed the presence of newly formed bone and large areas of osseointegration between the biocomposite and the tissue; this was not observed in the pure collagen samples. This finding would seem to indicate that the silica particles in the collagen promoted new bone formation. In this regard, Si has been shown to be essential to connective tissue formation, osteoblast proliferation, and bone mineralization. ${ }^{28}$ Beck Jr et al., ${ }^{29}$ showed that $50 \mathrm{~nm}$ silica-based nanoparticles stimulate osteoblast differentiation and mineralization and suppress osteoclast differentiation in vitro, and enhance bone mineral density in vivo.

Type I collagen has been reported to be ideal for fabrication of scaffolds for tissue engineering. ${ }^{4,30,31}$ The obtained results showed that the type I collagen matrix obtained following the method described here was an optimum scaffold component of the biocomposite, promoting cell adhesion and proliferation and favoring new bone formation. The aim of this work was to synthesize a composite using $\mathrm{SiO}_{2}$ particle as the mineral phase. It must be pointed out, however, that collagen can be combined with a ceramic material using other approaches, such as biomineralization and intrafibrillar silicification of collagen fibrils. ${ }^{32-34}$

There is extensive research on a number of forms of silicon, including bioactive glass, silica particles, and silica xerogels. Bioactive glasses are bioceramics that are solid, nonporous, and hard materials and that consist of a main component of silicon dioxide (or silicate) and three other components: sodium dioxide, calcium oxide, and 
phosphorous. By modifying the components, different forms of bioactive glasses can be made. ${ }^{35}$ Bioactive glasses have been widely used for bone tissue regeneration purposes with good results. For instance, 45S5 Bioglass has been reported to have intracellular effects on the proliferation of osteoblasts due to the release of soluble silica and other ionic species, as well as extracellular effects because of the high-surface area and nanometer-scale porosity of the hydrated silica gel and hydroxycarbonate apatite layers that rapidly form. ${ }^{36}$ The present study focused on evaluating the impact of silicon in the form of silica particles within a collagen matrix on bone tissue response. In this regard, previous published reports showed that $\mathrm{SiO}_{2}$ nanoparticle size contributed to osteoblast differentiation, with smaller particles $(50-100 \mathrm{~nm})$ having greater stimulatory effects on osteoblast stimulation and differentiation than $450 \mathrm{~nm} \cdot{ }^{14}$ A study conducted by our research group showed that mesoporous silica particles incubated with mesenchymal cells had the ability to promote cell differentiation, resulting in a significant increase in alkaline phosphatase activity. ${ }^{18}$ To sum up, in vitro studies have shown that the use of silica-based particles is a promising strategy in bone tissue engineering. Previously reported studies evaluating different uses of biomaterials with similar properties, such as drug delivery and wound healing, have shown encouraging results. ${ }^{37,38}$ We sought to explore the usefulness of $\mathrm{Si}$ particles applied for a different purpose. In addition, histological examination of the $\mathrm{C} / \mathrm{Sol}$-Si showed the presence of granule-like agglomerates of a finely particulate material inside the bone marrow. It could be posited that the biomaterial developed here could act as a reservoir of silica, so that upon collagen degradation, the silica particles would be released into the microenvironment promoting bone repair. Although the chemical composition of the deposits observed in the tissue (bone marrow) was not analyzed by energy dispersive spectroscopy (EDS), the fact that histological examination revealed no deposits in pure collagen samples is an indication that they are likely silica particles originating from the biocomposite. Nevertheless, there is no conclusive evidence in the literature on the cytotoxic, genotoxic, or carcinogenic effects of the degradation of bone substitutes containing $\mathrm{Si}^{39}$ The Si particles were not found to aggregate when observed by SEM but formed agglomerates when implanted in the bone marrow. The aggregation state and the surface area of some nanoparticulate materials can change once they are placed in the biological milieu. The levels of particle aggregation should be taken into account when considering size and dose-dependent toxicity. ${ }^{40}$

It is well documented that agglomeration of particles in the tissues triggers giant cell recruitment. ${ }^{41}$ However, this cell type was not observed in the present study. Moreover, no inflammatory infiltrate related with the agglomerates was observed. The absence of these cell types could be attributed to factors such as particle size and distribution, aggregation state, shape, crystalline structure, chemical composition, surface area and charge, and porosity. ${ }^{42,43}$ The silica particles $(500 \mathrm{~nm})$ formed agglomerates in the tissues and seemed to act as "larger structures" with different surface roughness; it is possible that the body recognizes the agglomerated particles as microparticles instead of nanoparticles, and this may account for the absence of an inflammatory response. ${ }^{44}$ The obtained results show that the particles have good biocompatibility.
The fact that bone tissue is composed of collagen-mineralized fibrils has led to the development of many collagen-based biomaterials in the pursuit of mimicking the bone structure as accurately as possible for tissue engineering purposes. As a result of advances in manufacturing technologies, an increasing number of novel biomaterials are being fabricated. Nevertheless, the suitability of a biomaterial designed for bone tissue engineering cannot be confirmed until it is tested in an in vivo experimental model. Physicochemical characterization and biological evaluation of these materials is necessary to assess their potential use as bone substitutes.

The present study explored an easy to synthesize C/Sol-Si consisting of a packed-collagen fibrils matrix combined with silica particles that acts as a scaffold for bone repair and showed it to be a promising material for use in bone tissue engineering. The results of the in vitro swelling test allow inferring that the biocomposite would swell early after implantation in vivo. The biocomposite obtained here could therefore be suitable for cell attachment, promoting bone tissue regeneration under physiological conditions. Furthermore, as shown by the MTT assay, the cytotoxic effect of the collagen-silica composite described here was low, and it can therefore be considered a potential material for biomedical applications. ${ }^{45}$

In addition, based on the results of the in vitro degradation test using collagenase type I, it could be thought that collagenase would degrade the collagen fibrils in the biocomposite thus promoting in vivo bone regeneration. Biodegradable polymers generally possess hydrolytically unstable linkages in their chains. In particular, the degradation and decomposition of collagen fibrils is an important issue on account of the widespread use of collagen as a biomaterial in diverse applications including fabrication of suture material and prosthetic devices. Collagenase seems to degrade collagen fibrils in a nonspecific manner, degrading the fibrils along their length but without splitting them into multiple fragments. ${ }^{46}$

The biocomposite designed and evaluated in the present study showed good biocompatibility in the in vivo experimental model used here. Further studies are necessary to assess tissue response at longer experimental time points and to evaluate the biological behavior of the biocomposite matrix and its replacement with newly formed lamellar bone over time. Moreover, the finding of lamellar bone will allow histomorphometric evaluation of tissue response to the biomaterial. The ability of the silica particles observed inside the bone marrow to promote new bone formation will be assessed in future studies. The originality of the present study is that we assessed in vivo the suitability of the $\mathrm{C} / \mathrm{Sol}-\mathrm{Si}$ as a potential biomaterial for bone tissue engineering.

\section{ACKNOWLEDGMENTS}

MI Alvarez Echazú is grateful for her postdoctoral fellowship granted by the National Council for Scientific and Technological Research, Argentina (CONICET). The authors would like to acknowledge the support of grants UBACYT 20020190100148BA, 20020150100 032BA, and UBACYT 20020110100081 from the University of Buenos Aires; grant PIP 11220130100091 from the CONICET, grant FOUBA Res. (CD) N ${ }^{\circ} 330 / 19-01$ from the School of Dentistry of the 
University of Buenos Aires, and grant PICT 2015-2922 from National Agency for the Promotion of Science and Technology. The authors thank Dr Romina Glisoni for the use of the DLS equipment (Instituto NANOBIOTEC UBA-CONICET, Cátedra Tecnología Farmacéutica II FFyB-UBA).

\section{DATA AVAILABILITY STATEMENT}

Data available on request from the authors

\section{ORCID}

Martin Desimone (D) https://orcid.org/0000-0002-0571-7962

Daniel Olmedo (D) https://orcid.org/0000-0002-2084-6973

\section{REFERENCES}

1. Li M, Zhang $X$, Jia $W$, et al. Improving in vitro biocompatibility on biomimetic mineralized collagen bone materials modified with hyaluronic acid oligosaccharide. Mater Sci Eng C. 2019;104:110008.

2. Soufdoost RS, Yazdanian M, Tahmasebi E, et al. In vitro and in vivo evaluation of novel Tadalafil/ $\beta$-TCP/collagen scaffold for bone regeneration: a rabbit critical-size calvarial defect study. Biocybern Biomed Eng. 2019;39:789-796.

3. Reznikov N, Shahar R, Weiner S. Bone hierarchical structure in three dimensions. Acta Biomater. 2014;10:3815-3826.

4. Martínez C, Fernández C, Prado M, Ozols A, Olmedo DG. Synthesis and characterization of a novel scaffold for bone tissue engineering based on Wharton's jelly. Journal of Biomedical Materials Research Part A, 2017;105(4):1034-1045. https://doi.org/10.1002/jbm.a.35976

5. Xia Z, Yu X, Jiang X, Brody $H$, Rowe D, Wei M. Fabrication and characterization of biomimetic collagen-apatite scaffolds with tunable structures for bone tissue engineering. Acta Biomaterialia, 2013;9(7):7308-7319. https://doi.org/10.1016/j. actbio.2013.03.038

6. Dhand C, Ong ST, Dwivedi N, et al. Bio-inspired in situ crosslinking and mineralization of electrospun collagen scaffolds for bone tissue engineering. Biomaterials. 2016;104:323-338.

7. Binkley DM, Grandfield K. Advances in multiscale characterization techniques of bone and biomaterials interfaces. ACS Biomater Sci Eng Am Chem Soc. 2018;4:3678-3690.

8. Diez-Escudero A, Espanol M, Ginebra M-P. Synthetic bone graft substitutes: calcium-based biomaterials. In: Alghamdi H, eds. Woodhead Publishing; 2020:125-157. https://doi.org/10.1016/B978-0-08-1024 78-2.00006-4

9. Giraud-Guille M-M, Belamie E, Mosser G, Helary C, Gobeaux F, Vigier S. Liquid crystalline properties of type I collagen: Perspectives in tissue morphogenesis. Comptes Rendus Chimie, 2008;11(3):245252. https://doi.org/10.1016/j.crci.2007.05.005

10. Giraud Guille MM, Mosser G, Helary C, Eglin D. Bone matrix like assemblies of collagen: from liquid crystals to gels and biomimetic materials. Micron. 2005;36:602-608.

11. Desimone MF, Hélary C, Rietveld IB, et al. Silica-collagen bionanocomposites as three-dimensional scaffolds for fibroblast immobilization. Acta Biomater. 2010;6:3998-4004.

12. Echazu MIA, Tuttolomondo MV, Foglia ML, et al. Advances in collagen, chitosan and silica biomaterials for oral tissue regeneration: from basics to clinical trials. J Mater Chem B Royal Soc Chem. 2016;4:69136929.

13. Arcos D, Vallet-Regí M. Sol-gel silica-based biomaterials and bone tissue regeneration. Acta Biomaterialia, 2010;6(8):2874-2888. https:// doi.org/10.1016/j.actbio.2010.02.012

14. Ha S-W, Viggeswarapu M, Habib MM, Beck GR. Bioactive effects of silica nanoparticles on bone cells are size, surface, and composition dependent. Acta Biomater. 2018;82:184-196.
15. Mebert AM, Baglole CJ, Desimone MF, Maysinger D. Nanoengineered silica: properties, applications and toxicity. Food Chem Toxicol. 2017;109:753-770.

16. O'Neill E, Awale G, Daneshmandi L, Umerah O, Lo KW-H. The roles of ions on bone regeneration. Drug Discov Today. 2018;23:879-890.

17. Stöber W, Fink A, Bohn E. Controlled growth of monodisperse silica spheres in the micron size range. Journal of Colloid and Interface Science. 1968;26(1):62-69. https://doi.org/10.1016/0021-9797(68) 90272-5

18. Alvarez GS, Alvarez Echazú MI, Olivetti CE, Desimone MF. Synthesis and characterization of ibandronate-loaded silica nanoparticles and collagen nanocomposites. Curr Pharm Biotechnol. 2015;16: 661-667.

19. Bergman I, Loxley R. Two Improved and Simplified Methods for the Spectrophotometric Determination of Hydroxyproline. Analytical Chemistry, 1963;35(12):1961-1965. https://doi.org/10.1021/ac60205a053

20. Cabrini RL, Guglielmotti MB, Almagro JC. Histomorphometry of initial bone healing around zirconium implants in rats. Implant Dent. 1993;2: 264-267.

21. Perumal S, Ramadass SK, Gopinath A, et al. Altering the concentration of silica tunes the functional properties of collagen-silica composite scaffolds to suit various clinical requirements. J Mech Behav Biomed Mater. 2015;52:131-138.

22. Jiang $\mathrm{X}$, Tang $\mathrm{X}$, Tang L, Zhang B, Mao H. Synthesis and formation mechanism of amorphous silica particles via sol-gel process with tetraethylorthosilicate. Ceramics International, 2019;45(6):7673-7680. https://doi.org/10.1016/j.ceramint.2019.01.067

23. Zamani D, Moztarzadeh F, Bizari D. Alginate-bioactive glass containing $\mathrm{Zn}$ and $\mathrm{mg}$ composite scaffolds for bone tissue engineering. Int J Biol Macromol. 2019;137:1256-1267.

24. Lönnroth EC. Toxicity of medical glove materials: a pilot study. Int $J$ Occup Saf Ergon. 2005;11:131-139.

25. Markov PA, Krachkovsky NS, Durnev EA, et al. Mechanical properties, structure, bioadhesion, and biocompatibility of pectin hydrogels. J Biomed Mater Res - Part A. 2017;105:2572-2581.

26. Wingender B, Bradley $P$, Saxena N, et al. Biomimetic organization of collagen matrices to template bone-like microstructures. Matrix Biol. 2016;52-54:384-396.

27. Kanczler JM, Wells JA, Gibbs DMR, Marshall, KM, Tang, DKO, Oreffo, ROC. Bone tissue engineering and bone regeneration. In: Lanza R, Langer R, Vacanti JP, Atala A, eds. Principles of Tissue Engineering. London: Elsevier; 2020:917-935. https://doi.org/10.1016/ B978-0-12-818422-6.00052-6

28. Jugdaohsingh R. Silicon and bone health. J Nutr Health Aging. 2007; 11:99-110.

29. Beck GR, Ha S-W, Camalier CE, et al. Bioactive silica-based nanoparticles stimulate bone-forming osteoblasts, suppress boneresorbing osteoclasts, and enhance bone mineral density in vivo. Nanomedicine. 2012;8:793-803.

30. Brown RA, Phillips JB. Cell responses to biomimetic protein scaffolds used in tissue repair and engineering. Int Rev Cytol. 2007;262:75-150.

31. Jones I, Currie L, Martin R. A guide to biological skin substitutes. $\mathrm{Br} J$ Plast Surg. 2002;55:185-193.

32. Jiang $\mathrm{S}$, Wang $\mathrm{M}, \mathrm{He} \mathrm{J}$. A review of biomimetic scaffolds for bone regeneration: toward a cell-free strategy. Bioeng Transl Med. 2021;6: e10206.

33. Hu C, Yu Le, Wei Mei. Biomimetic intrafibrillar silicification of collagen fibrils through a one-step collagen self-assembly/silicification approach. RSC Advances, 2017;7(55):34624-34632. https://doi.org/ 10.1039/c7ra02935g

34. Yu L, Wei M. Biomineralization of collagen-based materials for hard tissue repair. Int J Mol Sci. 2021;22:944.

35. van van Vugt TA, Geurts JAP, Arts JJ, Lindfors NC. Biomaterials in treatment of orthopedic infections. In: Arts JJC, Geurts J, eds. Management of Periprosthetic Joint Infections (PJIs). Amsterdam: 
Woodhead Publishing; 2017:41-68. https://doi.org/10.1016/B9780-08-100205-6.00003-3

36. Fiume E, Barberi J, Verné E, Baino F. Bioactive glasses: from parent $45 S 5$ composition to scaffold-assisted tissue-healing therapies. J Funct Biomater. 2018;9:24.

37. Mebert AM, Alvarez GS, Peroni R, et al. Collagen-silica nanocomposites as dermal dressings preventing infection in vivo. Mater Sci Eng C. 2018;93:170-177.

38. Foglia ML, Mitarotonda R, De Marzi MC, Desimone MF. Silicified collagen materials: modulation of the in vitro and in vivo response. Mater Sci Eng C. 2019;99:47-56.

39. Götz W, Tobiasch E, Witzleben S, Schulze M. Effects of silicon compounds on biomineralization, osteogenesis, and hard tissue formation. Pharm MDPI. 2019;11:117.

40. L'Azou B, Jorly J, On D, et al. In vitro effects of nanoparticles on renal cells. Part Fibre Toxicol. 2008;5:22.

41. Revell PA. The biological effects of nanoparticles. Nanotechnol Percept. 2006;2:283-298.

42. Oberdörster G, Maynard A, Donaldson K, et al. Principles for characterizing the potential human health effects from exposure to nanomaterials: elements of a screening strategy. Part Fibre Toxicol. 2005;2:8.

43. Bruno ME, Tasat DR, Ramos E, et al. Impact through time of different sized titanium dioxide particles on biochemical and histopathological parameters. J Biomed Mater Res A. 2014;102:1439-1448.
44. Guglielmotti MB, Domingo MG, Steimetz T, Ramos E, Paparella ML, Olmedo DG. Migration of titanium dioxide microparticles and nanoparticles through the body and deposition in the gingiva: an experimental study in rats. Eur J Oral Sci. 2015;123: 242-248.

45. Barrioni BR, de Carvalho SM, Oréfice RL, et al. Synthesis and characterization of biodegradable polyurethane films based on HDI with hydrolyzable crosslinked bonds and a homogeneous structure for biomedical applications. Mater Sci Eng C. 2015;52:22-30.

46. Paige MF, Lin AC, Goh MC. Real-time enzymatic biodegradation of collagen fibrils monitored by atomic force microscopy. Int Biodeter Biodegr. 2002;50:1-10.

How to cite this article: Alvarez Echazú, M., Renou, S., Alvarez, G., Desimone, M., \& Olmedo, D. (2021). A collagen-silica-based biocomposite for potential application in bone tissue engineering. Journal of Biomedical Materials

Research Part A, 1-10. https://doi.org/10.1002/jbm.a.37291 